\title{
ARE WE REALLY THAT CLUELESS?
}

\author{
David A. Gerber
}

University at Buffalo (SUNY)

Jonathan Zimmerman has written a smart book that sparkles with sly humor and clever, articulate observation. How could he fail? His material is a bonanza, and many of his intended audience of academic professionals are eager to receive it. He has traced over 150 years of complaints about poor teaching in American colleges and universities, and he has found that from one era to the next the complaints sound at their core much the same. Throughout, many students have been bored, sarcastic and cynical, and their instructors have remained variously clueless, defensive, indifferent, frustrated, confused, and helpless.

Here we have, from the standpoint of formal education, the smartest people in the country seeming to fail again and again, and their insights into how to improve their teaching frustrated and ultimately laid aside, until picked up again, often to be explained in a different critical vocabulary that is down through time philosophical, or behaviorist, or experiential. It's like those related, oft-proposed revisions we are all familiar with in the undergraduate curriculum, prompted by the felt-need for adjustment in the values or knowledge we are trying to impart and by the ever-intrusive bottom line, whether that budgetary "pie" is expanding or, as more often the case, fixed or contracting. You know, the ones in which, if you have been around long enough, you find yourself saying, "Didn't we try this already?" And you watch your younger colleagues, who can't know what you're talking about, buy in enthusiastically. Zimmerman memorably summarizes the situation, writing of a faculty veteran responding to the establishment of a "Center for Learning and Instruction" on his campus by saying something to the effect, "Isn't that what the college itself is supposed to be?" Such wicked ironies expressed by such smart people are the self-referential parody of our pretensions which delight many faculty.

While I value what Zimmerman has done for its wit and often keen observations into academic foibles, I cannot go the distance with him. I am critical of his largely offhand and vague invocations of "professional standards," best practices, and scientific knowledge of how learning is accomplished that provide the illusive background by which the amateurs are supposed to be separated from the professionals (Ken Bain has done the work of attempting to spell out best practices - what works - in plain language in What the Best College Teachers $\left.D o^{1}\right)$. Zimmerman himself seems to throw up his hands toward the end of his book, and say, as he observes repeatedly generations of faculty observers have said, "You either have it or you don't!" In other words, some adults are blessed with the illusive combination of charisma, engagement, humility and chutzpah, patience, charm, humor, and abilities to clearly summarize, analyze, and explain that make it possible to effectively instruct American adolescents. The best practices seem to come naturally to these people. They may not even have to think much about what they are doing. Others, for want of that awesome list of traits, or because they are simply too distracted by private concerns, or because they are preoccupied with research and publishing-i.e., what it is that we really get known for among peers and gets us promoted and our salary increased-seem to find them illusive. Some don't care about achieving them. Fortunately, most of us keep trying.

I also need to see from Zimmerman more attention paid to a series of practical, related differences in teaching situations that call for finer conceptual distinctions in figuring out what we mean when we speak of good and poor teaching. There are, of course, many teaching situations. For example, there is the wide variety of disciplines present in colleges and universities. As the freshman engineering students, whom I have been teaching, as a historian, for years about Supreme Court First Amendment decisions, have told me again and again, my class engages them at a level at which they are challenged as citizens, and hence "makes them think." I seem to care about what they believe about what Ken Bain refers to as the "big question" that captivate many

\footnotetext{
${ }^{1}$ Ken Bain, What the Best College Teachers Do (Cambridge, MA: Harvard University Press, 2004). Maggie Berg and Barbara K. Seeber, The Slow Professor: Challenging the Culture of Speed in the Academy (Toronto: University of Toronto Press, 2016) amplify Bain's analysis and point to growing institutional constraints, resulting from the corporatization of higher education, on establishing an atmosphere conducive to becoming engaged in teaching and inviting students to accompany you.
} 
student minds - and in my case, justice in all of its many dimensions. Their engineering professors don't to do that as much or in the same way, and they have to work a lot harder at balancing certification requirements and necessary technical disciplinary knowledge future bridge-builders, for example, need with the thinking citizens are challenged to do. I tell those students to listen to their engineering professors carefully, even as the whiteboard fills up with equations and calculations at 8:00 AM, if only because I don't want them building the sort of bridges that get hopelessly caught in a wind storm and sway those unfortunate enough to be on top of them and themselves to death. Related are the challenges we face in teaching large lecture courses that have to impart foundational information, as is the case in surveys like those history departments do from broad continental and chronological perspectives, and the upper division seminars that require the students to explain to us what they think and how they have come to think it. And related to that finally is one of the ultimate questions, to which Zimmerman seems to allude when he writes here and there about the state of our knowledge about the receptivity of students to learning. The students we confront in their first year are hopefully, and I think it is fair to say in my own experience definitely, not the same individuals when we encounter them as seniors. Their malleable brains have matured, and their behavior is more restrained and disciplined. As they contemplate their futures and prepare for the world beyond the campus, questions of identity and aspiration, as well as anxieties and apprehensions about what might become of them if they don't pay attention, have created a greater thoughtfulness and an openness to becoming engaged in learning. How we teach the 18-year-old and how we teach the 22-year-old must raise different questions for us, something for which those of us who have raised our own adolescents at home may well have a special sensitivity.

My own experience of long-struggling to improve my teaching is different than the sort Zimmerman suggests in focusing generally on formal, institutional efforts. In neglecting the examples posed by the individual instructor in the context of longtime, daily relations with colleagues in academic departments, he also neglects one of the principal ways in which instructors learn to improve themselves: casually, from one another. He does analyze departmental review processes of the sort that accompany promotion and tenure, which in my experience do not even count for much in those evaluations of individuals, though they do add to the anxieties of that process. They certainly do not improve anyone's teaching. Instead, I am thinking of the largely impromptu conversations among departmental colleagues about the common endeavor in which they are involved in creating a curriculum, working to refine it, and arguing about how to make it effective, and in teaching the same students, as individuals and as members of generational cohorts, through their four years in their courses. Not necessarily informed by any scientifically based knowledge about how students learn, but guided mostly by pragmatic adaptations about what works, this ongoing intradepartmental tutorial was, for me, the source of much practical knowledge. It also served as a means to collectively surmount, through mutual encouragement, the frustrations and failures that inevitably are a part of teaching day-in and day-out, week after week, semester after semester, year after year. I learned a great deal by thinking about what my colleagues, senior and junior alike, told me they were doing and had stopped doing. It came occasionally as a painful recognition of my limited imagination and laziness when repeating the same approaches, even when I didn't much like them and was aware that they didn't work very well in stimulating student engagement. ${ }^{2}$

But we shouldn't be too hard on ourselves. After all, though the world beyond the campus is hardly aware of it, instruction at the college and university level is hard work. Therefore, we might begin-while laughing with Zimmerman at how its challenges occasionally bring down the most bloated egos among us and mock our pretensions to be the masters of the universe-by acknowledging those difficulties inherent in the task, while putting our faces into the wind and attempting to improve.

\footnotetext{
${ }^{2}$ Berg and Seeber, "Collegiality and Community, pp. 71-90, in The Slow Professor, raise the issue of the ways in which the widely observed decline in collegiality in academic departments, which they attribute to the increasingly corporatization of universities and colleges, takes away the possibilities for precisely this sort of productive, informal interaction.
} 